\title{
Experimental analysis of the water retention behaviour of shales
}

\author{
Alessio Ferrari ${ }^{\text {a,*}}$, Valentina Favero ${ }^{a}$, Paul Marschall ${ }^{\mathrm{b}}$, Lyesse Laloui ${ }^{\mathrm{a}, \mathrm{c}}$ \\ a Ecole Polytechnique Fédérale de Lausanne (EPFL), School of Architecture, Civil and Environmental Engineering (ENAC), Laboratory for Soil Mechanics (LMS), \\ EPFL-ENAC-LMS, Station 18, CH-1015 Lausanne, Switzerland \\ ${ }^{\mathrm{b}}$ NAGRA, Hardstrasse 73, 5430 Wettingen, Switzerland \\ ${ }^{\mathrm{c}}$ King Abdulaziz University, Jeddah, Saudi Arabia
}

\section{A R T I C L E I N F O}

\section{Article history:}

Received 13 January 2014

Received in revised form

25 July 2014

Accepted 25 August 2014

\section{Keywords:}

Shales

Water retention behaviour

Opalinus Clay

Suction

Nuclear waste disposal

\begin{abstract}
A B S T R A C T
Shales are among the most commonly considered geomaterials in current energy-related geomechanical investigations, as they are involved in engineering applications such as the extraction of natural gas, $\mathrm{CO}_{2}$ sequestration and nuclear waste storage. A deep understanding of their behaviour with regard to variations in the degree of saturation is of significance for such applications. With the aim to establish a sound protocol for shale retention behaviour analysis, this paper presents an experimental methodology that takes into account the specificities of shales such as small pore size dimensions and the large variations in water potential to be applied to induce significant changes in the degree of saturation. The technique involves the direct control of the shale water content and the subsequent measurement of the suction at equilibrium by a psychrometer. A fluid displacement technique with a non-polar liquid is also used to assess the volume changes of the shale and to compute the degree of saturation. Selected test results are presented for various shale samples that have been cored at different depths. The results indicate that important features of the retention behaviour of geomaterials are fundamental aspects to be considered when analysing the retention behaviour of shales, such as the existence of main wetting and drying paths, the hysteresis domain, and the dependency of the air entry value on the void ratio.
\end{abstract}

c) 2014 Elsevier Ltd. All rights reserved.

\section{Introduction}

The development of engineering activities involving shales such as the extraction of shale gas and shale oil, the geological storage of nuclear waste and $\mathrm{CO}_{2}$ sequestration, has led to an increasing interest in the geomechanical behaviour of these geomaterials. In the context of such engineering applications, a deep understanding of shale retention behaviour is of primary significance. Water retention mechanisms play a major role in fluid trapping due to the capillary forces in the two-phase flows in gas reservoirs as well as in the resaturation of shale formations after ventilation, as in the case of deep geological repositories. Wetting and drying episodes also have significant impacts on shale volumetric behaviour: swelling/shrinkage of shales may be caused by changes in suction or variations in the degree of saturation; additionally, significant swelling pressures may develop when volumetric expansion upon wetting is prevented.

In general, the water retention behaviour of geomaterials is expressed as a relationship between the pore water potential and the amount of water stored in the material; water retention curves represent this relationship. Suction is often used as the variable

\footnotetext{
* Corresponding author. Tel.: +41 2169323 24; fax: +41 216934153 .

E-mail address: alessio.ferrari@epfl.ch (A. Ferrari).
}

that expresses pore liquid chemical potential. Matric suction $(s)$ is the component of the potential that accounts for the effects related to the presence of the matrix (capillarity, osmotic mechanism and electrostatic forces) [1]. Osmotic, or solute suction $(\pi)$ expresses the component of the potential associated with the solute concentration in the aqueous solution that constitutes the pore liquid. Total suction $(\psi)$ is the sum of these two components and is directly related to the relative humidity and temperature established in the pore gaseous phase. The amount of water is quantified by the gravimetric water content (the ratio of the weight of the water to the weight of the solid phase, $w$ ) or the degree of saturation (the ratio of the water volume to the pore volume, $S_{r}$ ).

The main features of water retention behaviour are found in the existence of a main wetting path (starting from a dry condition) and a main drying path (starting from a saturated condition), which, for a given density, embrace all the possible hydraulic states of the material. Any hydraulic path that moves from a main drying curve to a main wetting curve (or vice versa) takes place inside this hysteresis domain and is defined as a scanning curve.

The determination of water retention curves is becoming a well-established practice for the characterisation of unsaturated soils. For clayey materials, the characteristics that are usually quantified are the air entry value (value of suction at which the material starts to desaturate in a main drying episode) and its 
dependency on the void ratio [2], the residual degree of saturation and the hysteresis upon wetting and drying cycling [3]. For compacted clays, attention has also been paid to the effects of the evolution of the microstructure on retention behaviour $[4,5]$. Numerical models have been developed to reproduce the retention behaviour that accounts for these highlighted features [5-8].

In spite of this information on unsaturated soil retention behaviour, knowledge on shale retention behaviour is still limited. Indeed, the strength and stiffness of shales are significantly influenced by the degree of saturation or, alternatively, by the suction, as highlighted by Valès et al. [9] for the case of Tournemire shale (France). Ramos da Silva et al. [10] reported a reduction in the UCS for Beringen shale (Belgium) to a fifth of the original value when the suction was decreased from 50 to $10 \mathrm{MPa}$.

Despite these recognised impacts, few experimental studies have been conducted to evaluate shale water retention properties in a comprehensive way. The limitation of the acquired information is even more evident when compared to the available experimental evidence on the retention behaviour of low-porosity compacted clays [3,11] and natural clays [12-15]. Schmitt et al. [16] presented data on the retention behaviour of Tournemire shale (France), which was obtained from porosimetry tests along with data on two different sandstones highlighting the higher suction range that is needed for the shale in order to observe appreciable variations in the degree of saturation. Ramos da Silva et al. [10] investigated the water retention curve for Beringen shale along drying paths and compared it to the curve for Lixhe chalk, asserting that suction of a magnitude greater by two orders was needed for the shale to dry the materials at a $90 \%$ degree of saturation. Information on the water retention behaviour of the Opalinus Clay shale (Switzerland) has been also provided. Muñoz [17] presented data on the evolution of the water content and the degree of saturation with total suction. Zhang et al. [18] compared the water retention curves of Opalinus Clay shale in free and constrained volume conditions and discovered that there is a significant increase in the water amount that can be stored in the material when it is allowed to swell during the wetting phase. Villar and Romero [19] determined the retention curve for Opalinus Clay shale in terms of matric and total suction for free and confined volume conditions; they reported air entry values in the range of 9$21 \mathrm{MPa}$ for free volume conditions and 15-35 MPa for confined conditions. Romero et al. [20] reported values of the air entry value of Opalinus Clay shale at different depths to be equal to 13 and $18 \mathrm{MPa}$, as obtained from mercury intrusion porosimetry. From the analysis of the available data, it appears that no investigation has been conducted to compose a comprehensive picture, containing all relevant features, of shale retention behaviour. In particular, to the authors' knowledge, the retention behaviour along scanning paths has not been experimentally investigated. This paper aims to provide a robust and complete experimental framework to analyse shale retention properties, highlighting and quantifying all the features of retention behaviour, such as the air entry value and its dependency on the void ratio, the hysteresis phenomena and the volumetric response to suction changes.

Total suction has been selected for this study as the suction component for describing shale retention behaviour. This choice is justified, considering that shales have high air entry pressures (several MPa) and that a wide range of suction values need to be taken into consideration to observe significant changes in the degree of saturation. Indeed, typical values of dominant pore sizes for shales are in the range of nanometers or dozens of nanometers (e.g., $20 \mathrm{~nm}$ for the Pierre shale [21]); the Young-Laplace equation would allow to compute that matric suction values in the order of dozens of MPa (approximately $7 \mathrm{MPa}$ for a pore size of $20 \mathrm{~nm}$ ) would be required in order to remove the water from pores with characteristic size in this range. On the other hand, most techniques for controlling and measuring matric suction are limited to a maximum suction of $1.5 \mathrm{MPa}$ [22]. However, it is a common practice in petroleum engineering to gather information on the relationship between matric suction and degree of saturation by the analysis of porosimetry tests [21]. In order to compare results in terms of matric and total suction, the osmotic component must be assessed; this aspect has been poorly addressed for shales. Laloui et al. [12] reported values of 12.13 MPa and 17.3 MPa for the matric and total suction, respectively, for a sandy facies Opalinus Clay shale at a $74 \%$ degree of saturation. When comparing the water retention curves in terms of total and matric suction for Opalinus clay shales, Villar and Romero [19] pointed out that no clear difference is observed between the two curves; however, the scattering of the data did not seem to allow for a precise assessment of the osmotic component.

In the following section, the developed experimental protocol is described first. We then present and analyse selected results from shales from the northern region of Switzerland in light of the proposed experimental methodology. Complementary information is gained from the analysis of the porosimetry tests. The assessment of the osmotic suction component is performed by independently measuring the total and the matric suction; these measurements are used to explain the difference between the water retention curve that was obtained using the porosimetry technique and the methodology that is proposed in this paper.

\section{An experimental technique to investigate the water retention behaviour of shales}

The developed experimental technique for determining shale retention behaviour is based on the direct control of the water content and the subsequent measurement of the total suction. Different hydraulic paths are considered in order to analyse the response of the material to wetting and drying episodes. The following sections provide details on the specimen preparation, water content control, suction measurement and volume change detection.

\subsection{Specimen preparation and water content control}

The material is obtained from a shale core: slices of approximately $7-8 \mathrm{~mm}$ in height are cut with a diamond saw without using water, and they are immediately divided into smaller specimens with lateral sizes of approximately $20 \mathrm{~mm}$. Three specimens are immediately tested to obtain the initial condition in terms of water content, void ratio and total suction, using the procedure detailed in the next sections. The initial measured void ratio is compared with the void ratio of the core in order to assess the quality of the obtained specimens. The main wetting and drying paths are sought first; to this aim the material is initially brought to a dry state or to a "zero-matric-suction" state, respectively. The dry state is obtained by placing the specimens in desiccators that contain silica gel and leaving them to dry for approximately three weeks (applied total suction of approximately $300 \mathrm{MPa}$ ) until no significant change in their weight can be detected. The "zeromatric-suction" condition is achieved by placing the specimens in a sealed-glass jar, within which a relative humidity of $100 \%$ is imposed; the specimens are wrapped in filter paper and rest on porous stones immersed in water; synthetic water (corresponding to the in-situ water composition) may be used for this initial wetting stage in order to preserve the initial osmotic suction of the material. The weight of the specimens is monitored using a precision balance $(0.001 \mathrm{~g})$, and the process is stopped once no further evolution is observed (usually in three weeks).

Once equilibration is achieved, the main wetting and drying paths can be determined. To obtain the main drying path, the equalized 
specimens are air-dried in a controlled way under laboratorycontrolled conditions $\left(T=22{ }^{\circ} \mathrm{C}, R H \approx 45 \%\right.$, equivalent total suction of about $110 \mathrm{MPa}$ ) or placed in a desiccator with silica gel for the driest states. During the drying, the weight of the specimens is monitored using a precision balance $(0.001 \mathrm{~g})$, and the process is halted once the target water content is reached; the specimens are then packed hermetically for three days to allow for internal redistribution of the water content. Preliminary testing showed that three days of curing time were sufficient for having a repeatable measurement of the total suction on the prepared specimens.

The procedure to obtain the main wetting path consists of the addition of a target amount of water, either by the gaseous phase (distilled water) or pouring small droplets of water (distilled or synthetic water) on the surface of the specimen with a small syringe. Synthetic water is used to ensure that the osmotic suction component is preserved. The internal redistribution of the water content is allowed for three days by keeping the specimens in hermetically closed containers.

When the retention properties are sought in terms of the degree of saturation, the measurement of the volume change upon water content evolution is required. This determination allows for the quantification of shale swelling/shrinkage behaviour related to suction variation under unstressed conditions. In this case, the specimen volume is measured just after the measurement of the total suction with a destructive technique. When the retention behaviour is sought only in terms of water content or a limited amount of core material is available, a different procedure is considered. This latter technique consists of a progressive drying or wetting of the same shale specimen; the water content control is performed following the procedure that was previously described. Because no volume measurement is conducted, the specimen can be equalized to a new target water content after the total suction for the previous step has been measured. In general, three specimens are submitted to the same hydraulic path, allowing for a more representative analysis.

\subsection{Suction measurement}

The total suction readings are taken on the equalized specimens by means of a dew-point chilled-mirror psychrometer (Decagon, WP4C) $[23,24]$. A schematic representation of the device is shown in Fig. 1. A mirror is placed inside a sealed chamber, and its temperature is precisely controlled by a thermoelectric (Peltier) cooler. The relative humidity is imposed by the shale specimen inside the sealed chamber where a fan is placed so that the environment reaches equilibrium. The temperature on the mirror is progressively lowered, and a photoelectric cell captures the exact moment condensation occurs in the mirror. The corresponding temperature of the specimen is measured using an infrared thermometer. The relative humidity, which is the ratio of the vapour pressure at the specimen temperature to the saturated vapour pressure of water at the same temperature, is obtained from the difference between the dew point

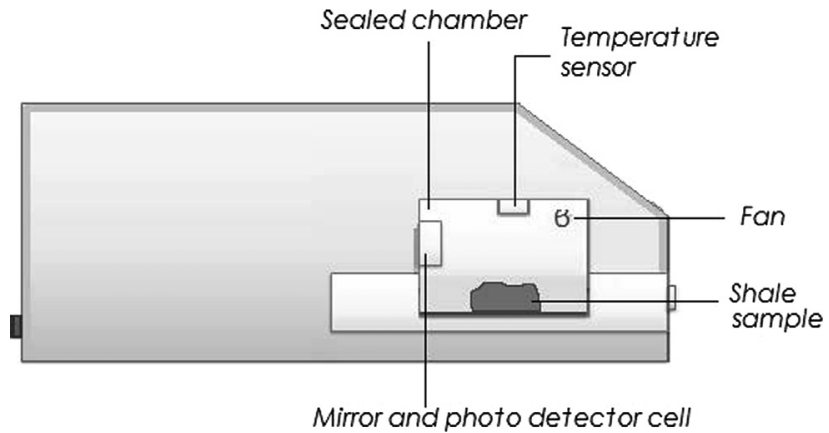

Fig. 1. Outline of the WP4C [26] chilled-mirror dew-point psychrometer with a shale fragment positioned inside the measuring chamber (after [23]). temperature on the mirror and the temperature of the specimen. Once the relative humidity is measured by the device, the total suction is obtained using the psychrometric law [25], which relates the relative humidity $(R H)$ and the absolute temperature $(T)$ to the total suction:

$\psi=-\frac{\rho_{w} R T}{M_{w}} \ln (\mathrm{RH})$

where $R$ is the universal gas constant and $\rho_{w}$ and $M_{w}$ are the density and the molecular mass of water, respectively.

The chilled-mirror dew point psychrometer is commonly used for suction measurement in natural and compacted soils [26]. The accuracy of the device as specified by the manufacturer is $\pm 0.05 \mathrm{MPa}$ for total suction from 0 to $5 \mathrm{MPa}$ and $1 \%$ for total suction in the range of 5-300 MPa. The manufacturer recommends that the specimen covers the entire surface of the sample holder. Due to the high suction values expected for shales and the fact that the shale specimens do not fill the entire sample holder, further analysis and calibrations have been conducted to assess the applicability of the device for analysing the water retention behaviour using shale fragments. Fig. 2 gives the total suction values read by the device for salt solutions at different temperatures of known water potential in the range of 4-393 MPa. An average accuracy of 3\% can be derived, except for the highest applied suction, and it is considered to be satisfactory for the purposes of this study.

The effects of the dimension of the specimen with respect to the size of the sample holder are analysed in Fig. 3. Tests were conducted at $25{ }^{\circ} \mathrm{C}$ by partially filling the sample holder with saturated $\mathrm{NaCl}$ and $\mathrm{KCl}$ solutions (reference total suction of $39.2 \mathrm{MPa}$ for the $\mathrm{NaCl}$ and 23.8 MPa for the $\mathrm{KCl}$ ). Fig. 3 shows a negligible influence of the percentage of the covered surface and height on the measurements because a maximum error of only $1.1 \%$ is observed for the suction readings. With this investigation, the suitability of this device for the total suction reading of shale fragments was confirmed.

\subsection{Assessment of volume change behaviour}

The method adopted for the volume measurement is based on a fluid displacement technique using a pycnometer filled with kerdane. Kerdane was selected for its immiscibility with water and its ability to invade the air-filled pore spaces of the surface without affecting the soil structure [27]. The analysis of the accuracy of this method, together with the precision in the estimation of the weight, allows for an estimation of the degree of saturation to be made with an accuracy of $4 \%$. The method used for volume determination is a

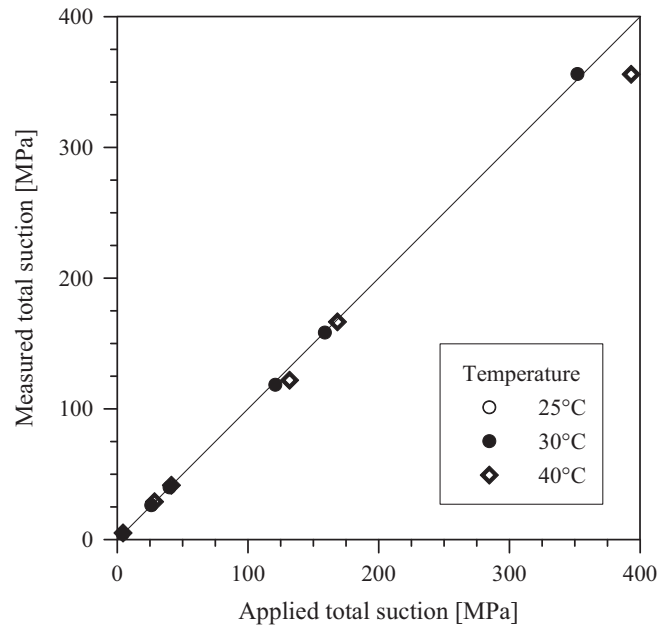

Fig. 2. Evaluation of the accuracy of the psychrometer in the range of measured suction when testing shale samples. 
destructive technique; a complete assessment of the retention behaviour in terms of main wetting and drying paths requires a large number of specimens to be prepared and tested (typically about fifty specimens). Other non-destructive techniques could be considered for this analysis (e.g., non-contact techniques such as laser scanning and micro computed tomography, or the use of wax for hydrostatic weighting as performed in [15]); however, in the experience gained through this work, difficulties in handling the shale specimens, especially at high water contents, make the applicability of these techniques inadvisable for the tested materials.

Complementary free swelling tests are also performed, for which the material is wetted in oedometric conditions, starting from its initial state, and the volume change is assessed through the continuous measurement of the heave of the specimen.

\section{Tested shales}

Three shales were considered in this study. Two of the considered shales come from a deep geothermal well near the village of Schlattingen in the Molasse Basin of Northern Switzerland; one

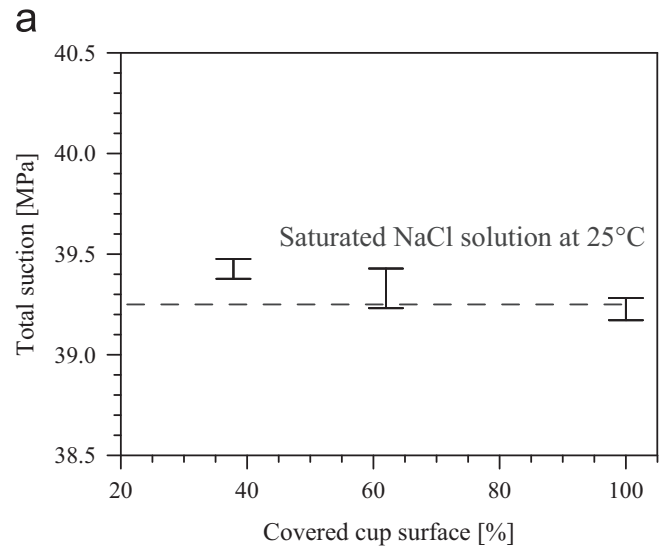

b

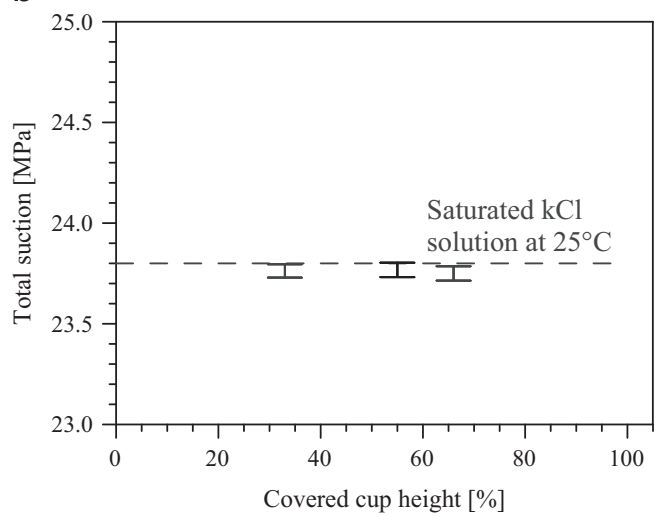

Fig. 3. Assessment of the errors in psychrometric readings associated with a partial filling of the sample holder by the shale fragment. belongs to the Opalinus Clay formation, and one to the so-called "Brown Dogger" formation. The third shale that was considered is Opalinus Clay, which comes from the Mont Terri Underground Research Laboratory (URL) in Northern Switzerland.

The Opalinus Clay from Schlattingen (OPA-deep) is the deepest shale formation considered in this study (depth of 837.44$891.25 \mathrm{~m}$ ); it consists mainly of claystone with a carbonate content of $10-20 \%$ and a quartz content in the range of $15-32 \%$. The "Brown Dogger" from Schlattingen (BD-deep) was extracted at a depth of 766.67-807.44 $\mathrm{m}$ and consists of silty to clay-rich marls with $30-50 \%$ carbonates and $20-25 \%$ quartz. The Opalinus Clay from the Mont Terri URL (OPA-shallow) from the shaly facies consists of dark grey silty, calcarerous shales with a typical content of $25-30 \%$ carbonate, $5-10 \%$ quartz and $10-15 \%$ biodetritus. Tested core samples were stored in PVC tubes filled with a layer of resin and constrained with metal frames immediately after the coring.

Index properties for the tested core samples are summarised in Table 1 , which reports the average particle density $\left(\rho_{s}\right)$, the bulk density $(\rho)$, the gravimetric water content $(w)$, the void ratio $(e)$, the degree of saturation $\left(S_{r}\right)$ and the Atterberg limits (the liquid limit $w_{L}$ and the plastic limit $w_{P}$ ). The OPA-deep cores present two different densities; the most superficial cores, indicated as OPAdeep', have a higher void ratio and water content compared to the deepest samples (OPA-deep"). Mineralogical analysis of the cores showed that the OPA-deep with higher porosity presents a reduced quartz content (approximately 17\%) with respect to the denser cores (typical value about 28\%) and slightly higher Atterberg limits.

Grain size distributions were obtained using an ad-hoc procedure that included material crashing, particle dispersion and sedimentation analysis [28], and they are reported in Fig. 4.

The porosity network has been analysed in terms of pore size density (PSD) functions, which have been determined using Mercury Intrusion Porosimetry (MIP). MIP includes the progressive penetration of mercury into a sample and the measurement of the intruded volume of mercury as a function of the applied pressure. Tests were conducted on freeze-dried samples by sublimation inside a vacuum chamber at 0.06 mbar and $-50{ }^{\circ} \mathrm{C}$ for $24 \mathrm{~h}$. MIP tests were performed in a Thermo Electron Corporations porosimeter that attained a maximum intrusion pressure of $400 \mathrm{MPa}$ (the corresponding minimum entrance pore size diameter was about $4 \mathrm{~nm}$ ). Apparent pore sizes were determined by applying corrections for compressibility changes of the various components of the equipment. The PSD was obtained according to the expression $\mathrm{PSD}=-\Delta \mathrm{e}_{\mathrm{HG}} / \Delta(\log d)$, where $d$ is the entrance pore size and $e_{H G}$ represents the void ratio intruded at each increment of the mercury pressure. The results of the MIP are reported in Fig. 5. The shape of PSDs, which are flat on the right side, suggest that the non-detected porosity (pores larger than the maximum pore size measured in MIP) is negligible. Unimodal PSD functions are found for all the tested shales, showing pore modes at approximately $20 \mathrm{~nm}$ for the OPA-shallow and BD-deep and at $8 \mathrm{~nm}$ for the OPA-deep'. The lower modal pore diameter for the OPA-deep' with respect to the BD-deep, in spite of the higher porosity, can be justified by considering the lower quartz content registered for the former; this reduced quartz content may imply a

Table 1

Geotechnical characteristics of the tested shales.

\begin{tabular}{|c|c|c|c|c|c|c|c|c|}
\hline Shale & depth (m) & $\rho_{s}\left(\mathrm{Mg} / \mathrm{m}^{3}\right)$ & $\rho\left(\mathrm{Mg} / \mathrm{m}^{3}\right)$ & $w(\%)$ & $e(-)$ & $S_{r}(\%)$ & $w_{L}(\%)$ & $w_{P}(\%)$ \\
\hline OPA-shallow & $\sim 300$ & 2.74 & 2.46 & 6.9 & 0.21 & 92 & 38 & 23 \\
\hline BD-deep & $767-807$ & 2.75 & $2.52-2.56$ & $2.7-4.4$ & $0.09-0.12$ & 69-99 & $25-33$ & $10-23$ \\
\hline OPA-deep' & $837-838$ & 2.74 & 2.49 & $4.3-4.9$ & $0.14-0.15$ & $80-94$ & $36-39$ & $22-25$ \\
\hline OPA-deep" & $855-891$ & 2.71 & $2.54-2.55$ & $3.3-3.6$ & $0.09-0.11$ & $93-96$ & $29-33$ & $19-22$ \\
\hline
\end{tabular}


reduced amount of larger pores formed at the contact between the clay particles and the coarser grains [29].

Synthetic waters were used in the experiments with the aim of recreating the in-situ pore water compositions for the cores that were extracted at Mont Terri [30] and at the Schlattingen site [31]. The osmotic suction of this synthetic water was measured by the dew-point psychrometer and resulted in values of 1.2 MPa for the Mont Terri synthetic water (OPA-shallow) and 0.98 MPa for the

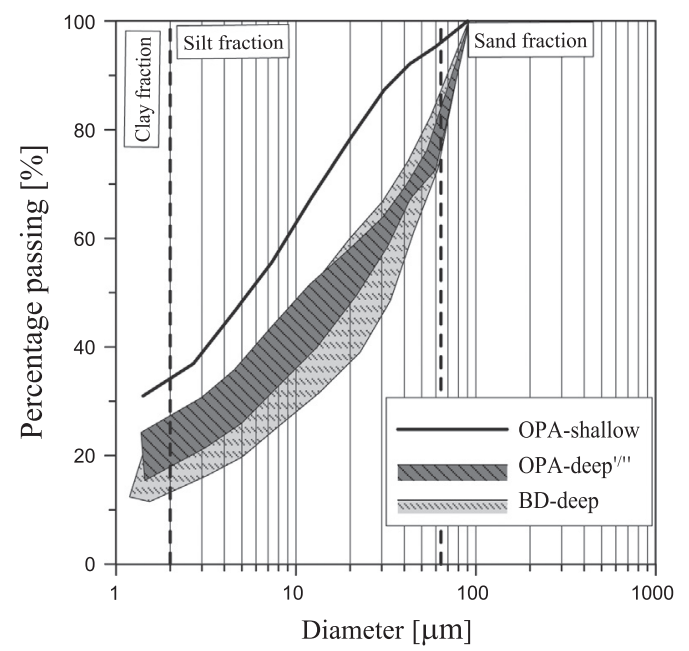

Fig. 4. Grain size distribution obtained from the analyses of one core for the OPAshallow, 5 cores for the OPA-deep and 6 cores for the BD-deep.

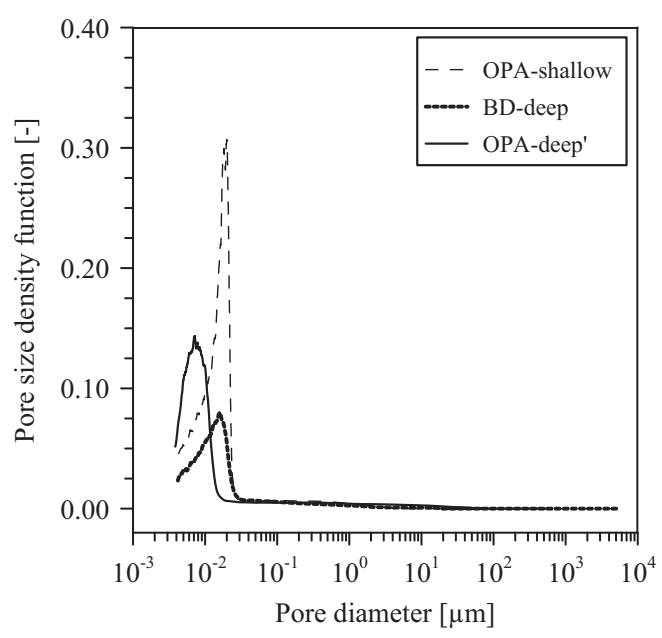

Fig. 5. Pore size density function of the tested shales.
Schlattingen synthetic water (BD-deep and OPA-deep). The testing programme is reported in Table 2 for each tested shale.

\section{Experimental results}

\subsection{Main drying and wetting paths}

The results obtained in the determination of the main wetting and drying paths for the OPA-shallow are shown in Fig. 6. The evolution of the water content with the total suction is shown in Fig. 6a; each point represents an average value of three specimens, which were brought to the same target water content value; their standard deviation is also represented. The initial condition corresponds to a water content of $6.7 \%$. For the specimens equalized to the "zero matric suction" state, the measured total suction was $1.4 \mathrm{MPa}$, which is in good agreement with the osmotic suction of the synthetic water used for this initial wetting. Starting from this state, the points obtained by the controlled drying procedure describe a progressive increase in total suction along with a reduction in water content; the driest state obtained with this procedure corresponds to a water content of $1.9 \%$ and a measured total suction of $134 \mathrm{MPa}$. This drying path tends to the residual condition that was achieved in the desiccator $(w=1.0 \%$, suction $=213 \mathrm{MPa}$ ), when the initial state for the main wetting path was sought. For all the tested specimens, volume measurements were obtained at the end of the equalisation stage. The obtained results are depicted in Fig. 9 in terms of void ratio versus total suction. Significant swelling/shrinkage behaviour was observed with suction variation. The void ratios obtained for the lowest measured suction are in very good agreement with the results of a free swelling test carried out with the same synthetic water used for determining the water retention curves. The void ratio reduction upon drying allows for the identification of the shrinkage limit. The suction value at which no significant volume reduction is observed (here defined when $\Delta e / \Delta \psi<0.1 \%$ ) is approximately $10 \mathrm{MPa}$; the corresponding shrinkage limit can be seen in Fig. 6a on the drying path and was found to be $6.4 \%$. The void ratio evolution with suction was fitted with the following incremental expression:

$\dot{e}=-\frac{\dot{\Psi}}{K_{r e f}}\left(\frac{\Psi_{r e f}}{\Psi}\right)^{m}\left(1+e_{0}\right)$

in which $K_{r e f}, \psi_{\text {ref }}$ and $m$ are the fitting parameters and $e_{0}$ is a reference void ratio. The values of the parameters obtained by the least square method are reported in Table 3. The retention curves in terms of the degree of saturation were obtained by combining the volume evolution and the water content along the wetting and drying paths. The results have been fitted with a Van Genuchten's

Table 2

Test programme

\begin{tabular}{|c|c|c|c|}
\hline Shale & Number of tested specimens & Hydraulic path & Void ratio measurement \\
\hline \multirow[t]{2}{*}{ OPA-shallow } & Main drying: 36 & Initial state $\rightarrow$ zero matric suction state $\rightarrow$ main drying & Yes \\
\hline & Initial state: 3 & Initial state $\rightarrow$ reference dry condition $\rightarrow$ main wetting & Yes \\
\hline \multirow[t]{2}{*}{ BD-deep } & $\begin{array}{l}\text { Main drying: } 21 \\
\text { Main wetting: } 24\end{array}$ & Initial state $\rightarrow$ zero matric suction state $\rightarrow$ main drying & Yes \\
\hline & Initial state: 3 & Initial state $\rightarrow$ reference dry condition $\rightarrow$ main wetting & Yes \\
\hline \multirow[t]{2}{*}{ OPA-deep' } & $\begin{array}{l}\text { Main drying: } 18 \\
\text { Main wetting: } 18\end{array}$ & Initial state $\rightarrow$ zero matric suction state $\rightarrow$ main drying & Yes \\
\hline & Initial state: 3 & Initial state $\rightarrow$ reference dry condition $\rightarrow$ main wetting & Yes \\
\hline OPA-deep" & 3 & Initial state $\rightarrow$ progressive rewetting $\rightarrow$ progressive drying & Inferred \\
\hline
\end{tabular}


type [32] expression:

$S_{r}=\left(1+\left(\frac{\Psi}{P}\right)^{n}\right)^{(-\lambda)}$

where $P, n$ and $\lambda$ are the fitting parameters; the fitting values obtained by the least square method are reported in Table 3.

The initial state for the OPA-shallow corresponds to a degree of saturation of $95 \%$; this value seems to confirm the fact that the material is reported to be saturated or close to saturation in situ; in addition, the initial state is found to be located along the main drying path as a consequence of the coring process and the exposure to the atmosphere before preservation. The main drying path allows for the identification of the maximum total suction value that the material can sustain without significant changes in the degree of saturation (air entry value, $\psi_{e}$ ). For the OPA-shallow, this value is $11 \mathrm{MPa}$ (taken as the total suction corresponding to $95 \%$ of the degree of saturation), and the corresponding void ratio is 0.19 . The main drying and wetting curves embrace the hysteresis domain of the material, which is significant for total suction values lower than $100 \mathrm{MPa}$ (Fig. 6b).

a

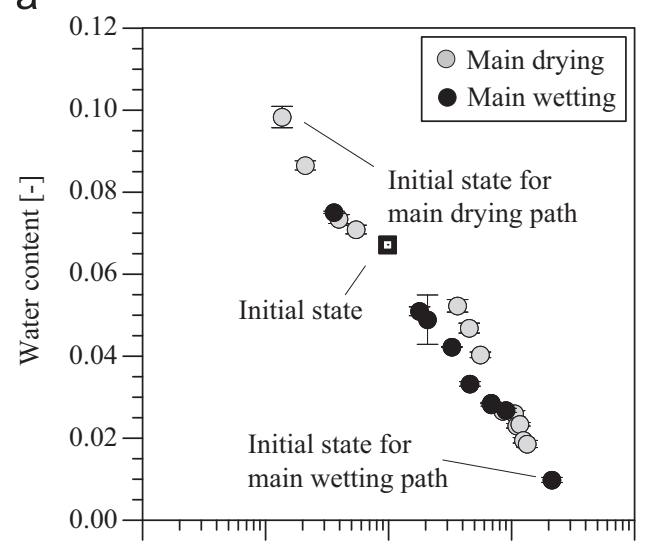

b

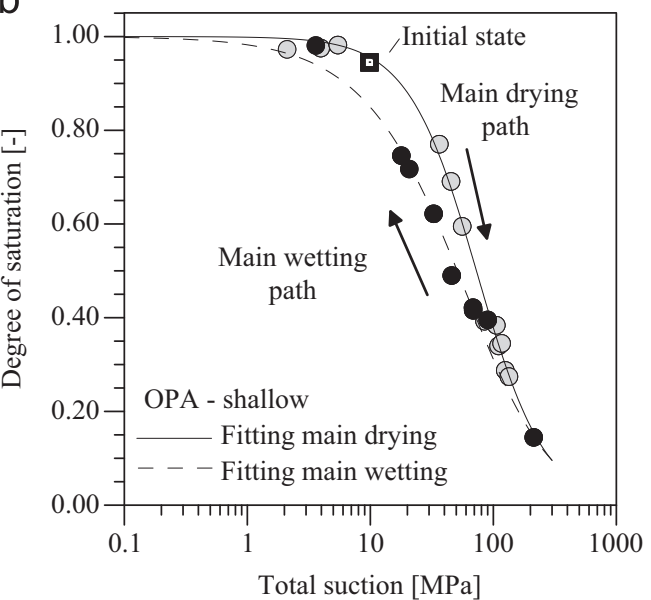

Fig. 6. Water retention behaviour of the OPA-shallow shale in terms of water content (a) and degree of saturation (b) as a function of the total suction.
Figs. 7 and 8 depict the results concerning the wetting and drying paths for the BD-deep and OPA-deep core samples, respectively. The water content evolution with total suction is shown in Figs. 7a and $8 \mathrm{a}$. The initial states correspond to a water content of $3.2 \%$ for both the BD-deep and OPA-deep' shale samples. For the BD-deep and OPA-deep' specimens that were equalized to the "zero matric suction" state, the measured total suction was $1.2 \mathrm{MPa}$, which is in good agreement with the osmotic suction of the synthetic water. The volume evolution for the two shales is reported in Fig. 9. Again, a good agreement is found with the result of a free swelling test carried out on a BD-deep sample using the same synthetic water. The observed shrinkage limits were found to be approximately $4.1 \%$ and $6.4 \%$ for the BD-deep and for the OPA-deep', respectively, which correspond to a total suction of approximately of $14 \mathrm{MPa}$ for both shales. The void ratio evolutions were fitted with Eq. (2), and their fitting parameters are reported in Table 3. Due to the limited quantity of available material for OPA-deep", a systematic analysis of the void ratio evolution with total suction was not possible. The results collected on this material are also shown in Fig. 9 along with the results of a free swelling test. The collected points align well with the trend registered for the BD-deep shale; in this sense, a unique trend

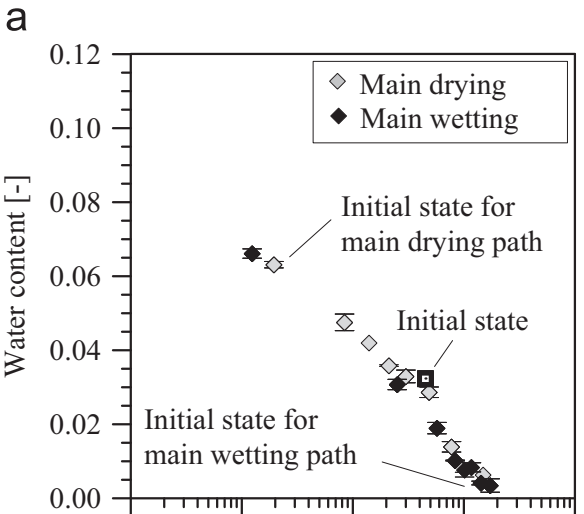

b

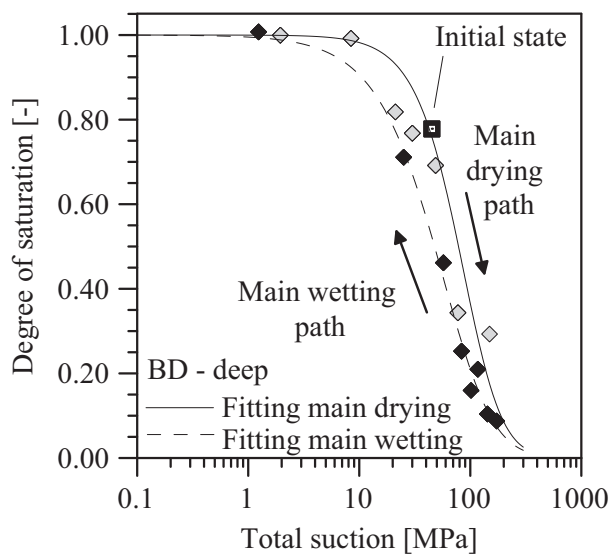

Fig. 7. Water retention behaviour of the BD-deep shale in terms of water content (a) and degree of saturation (b) as a function of the total suction.

Table 3

Values of the fitting parameters for volumetric and water retention behaviour.

\begin{tabular}{|c|c|c|c|c|c|c|c|c|c|c|}
\hline \multirow[t]{2}{*}{ Shale } & \multirow{2}{*}{$\begin{array}{l}K_{\text {ref }} \\
(\mathrm{MPa})\end{array}$} & \multirow{2}{*}{$\begin{array}{l}\psi_{\text {ref }} \\
(\mathrm{MPa})\end{array}$} & \multirow[t]{2}{*}{$m(-)$} & \multirow[t]{2}{*}{$e_{0}(-)$} & \multicolumn{2}{|l|}{$n(-)$} & \multicolumn{2}{|l|}{$P(\mathrm{MPa})$} & \multicolumn{2}{|l|}{$\lambda(-)$} \\
\hline & & & & & wetting & drying & wetting & drying & wetting & drying \\
\hline OPA-shallow & 14.66 & 1.62 & 2.63 & 0.31 & 0.98 & 1.53 & 110.13 & 78.17 & 1.80 & 1.08 \\
\hline BD-deep & 29.00 & 1.03 & 1.50 & 0.20 & 1.31 & 1.85 & 126.20 & 130.00 & 2.82 & 2.10 \\
\hline OPA-deep' & 45.00 & 0.98 & 1.30 & 0.22 & 1.16 & 2.05 & 30.00 & 49.00 & 0.63 & 0.42 \\
\hline
\end{tabular}



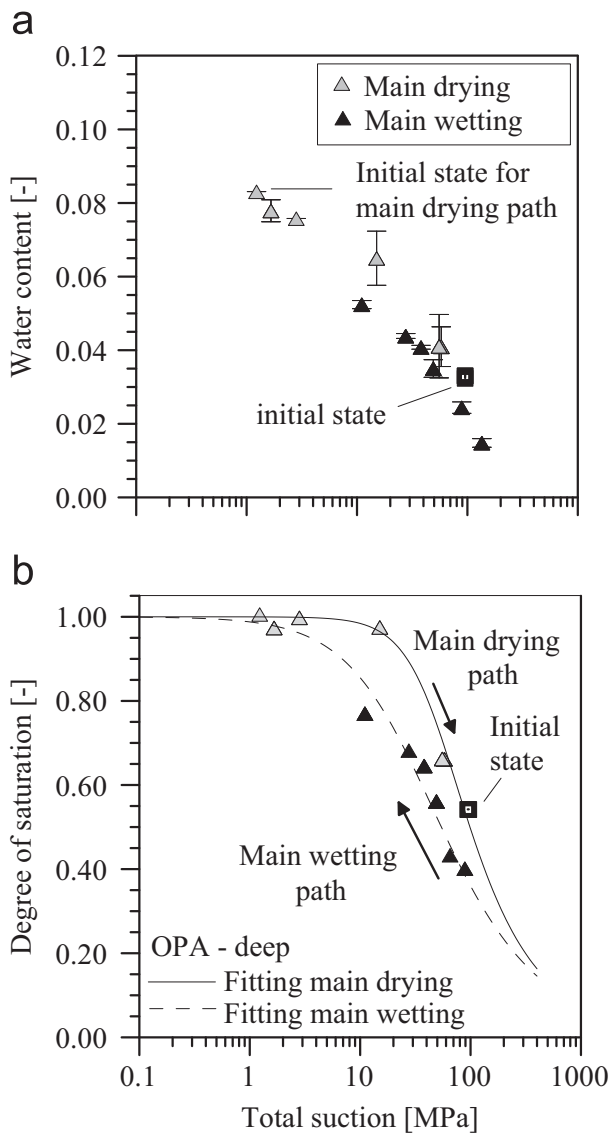

Fig. 8. Water retention behaviour of the OPA-deep' shale in terms of water content (a) and degree of saturation (b) as a function of the total suction.

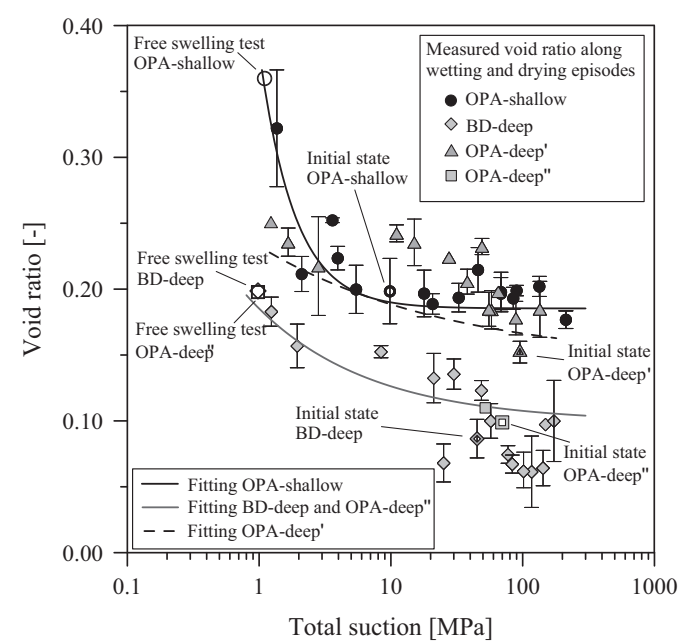

Fig. 9. Void ratio evolution as a function of the total suction for the various shale samples.

is used to describe the swelling/shrinkage behaviour for these two shales.

The analysis of the volumetric response to suction changes allows for the quantification of swelling potential for the tested shales. The measured volumetric deformations associated with the complete wetting of the material, starting from the driest condition, were $12.3 \%, 11.4 \%$ and $8.6 \%$, for OPA-shallow, BD-deep and OPA-deep, respectively. The highest swelling potential was observed for OPA-shallow; this behaviour can be explained by the higher clay content of this shale compared to the deep shales
(Fig. 4); in addition, greater depth and the diagenetic processes, which result in a higher degree of cementation, might be responsible for the lower swelling potential of the deepest shales. The retention curves in terms of the degree of saturation are reported in Figs. 7b and 8b for BD-deep and OPA-deep', respectively. The initial conditions correspond to a degree of saturation of $80 \%$ for BD-deep and 54\% for OPA-deep'. The registered low initial degree of saturation for OPA-deep' is attributed to a non-perfect preservation of the core used in the investigation. A general comparison of the retention behaviour of the tested shales reveals that very limited changes in the gravimetric water content are required for the deeper shales to undergo complete cycles of wetting and drying.

\subsection{Assessment of the scanning behaviour}

In order to gain additional information on the retention behaviour with cyclic variations of the water content, a wetting path was initiated for OPA-deep", starting directly from the initial state. The results are presented in Fig. 10. Three specimens were used, and they were progressively wetted following the procedure detailed in Section 2.1 until the material stopped showing a further tendency to absorb water. The corresponding total suction at this stage was approximately $2 \mathrm{MPa}$. The drying path was then initiated and carried out until a suction of $340 \mathrm{MPa}$ was reached.

The obtained results are represented in Fig. 11 in terms of degree of saturation versus total suction; the curve depicted in Fig. 9 for OPA-deep" was used for computing the evolution of the void ratio with total suction. In Fig. 11, the reference main wetting and drying retention curves for the OPA-deep are also represented. The initial wetting from the initial state (path $\mathrm{A}-\mathrm{B}$ ) takes place inside the hysteresis domain, and a scanning curve is clearly observed. As the hydraulic path encounters the main wetting curve, it follows this trend until saturation is reached (point C). Starting from this state, the hydraulic path follows the main drying path until the residual degree of saturation is reached (path $\mathrm{C}-\mathrm{D}$ ). The observed behaviour shows clearly that attention must be paid when wetting the shale, starting from its "as-extracted" state; in other words, the registered water contents may not be referred to a main wetting path, and this could have significant consequences when hydraulic properties, such as relative permeability, are sought.

\subsection{The air entry value}

The collected results on the retention properties of the tested shales provide information on the effects of the void ratio on the air entry value. Fig. 12 depicts the total suction and the void ratio

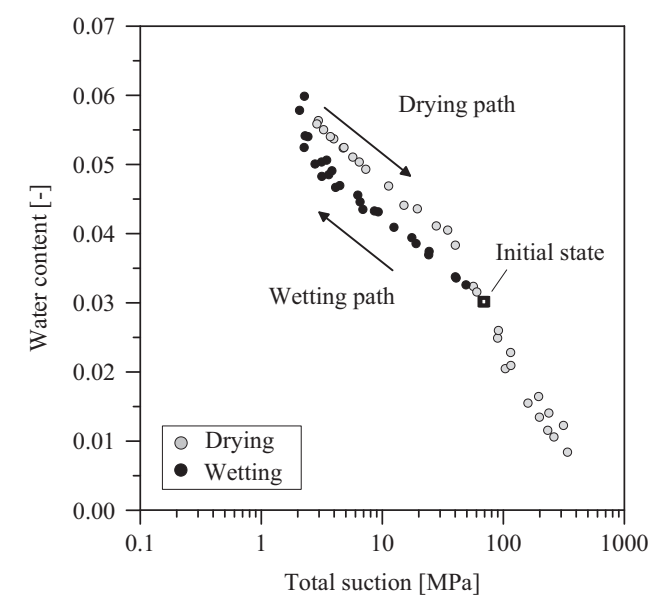

Fig. 10. Water retention behaviour of the OPA- deep" core sample. 


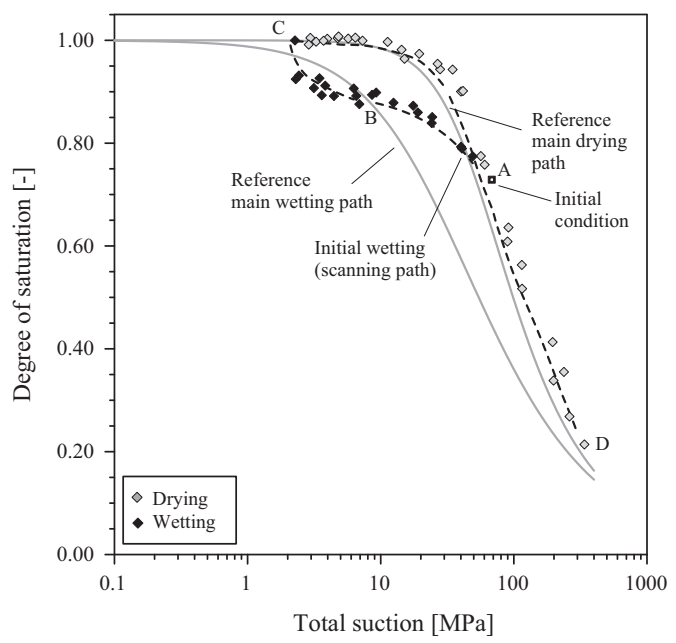

Fig. 11. Retention behaviour of an Opalinus Clay sample (OPA- deep") during wetting and drying cycling.

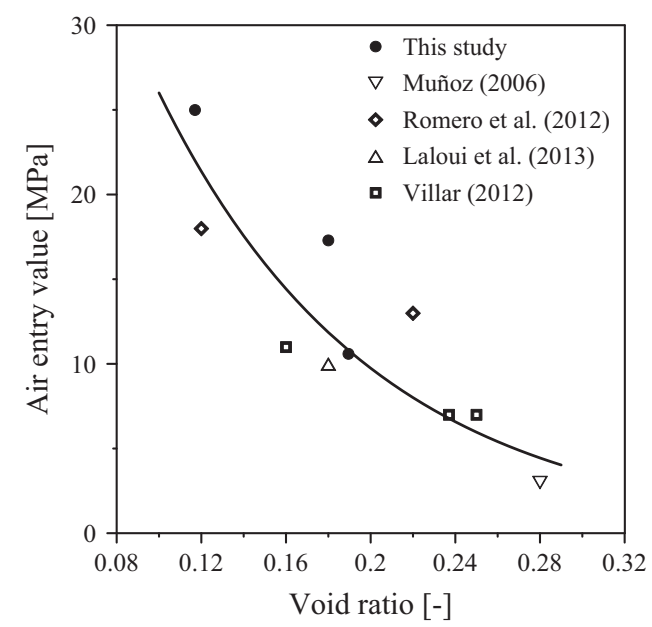

Fig. 12. Air entry values as a function of the void ratio for Opalinus Clay Shale.

at which the shales started to desaturate along the main drying paths. The results are supplemented with other available data from the literature for the Opalinus Clay. A unique exponential evolution function is proposed, and it captures the observed trend well:

$\Psi_{e}[\mathrm{MPa}]=69.39 \cdot \exp (-9.82 \cdot e)$

Using Eq. (1), the relative humidity values at which the shales start to desaturate can be calculated as a function of the void ratio. In Fig. 13, the minimum relative humidity to which the shales should be exposed in order to prevent desaturation is shown for a reference temperature of $22{ }^{\circ} \mathrm{C}$. This analysis may have an important application in the context of tunnel excavations in shale formations when the material is exposed to atmospheric conditions (ventilation phase in nuclear waste disposals). By combining the information with the cracking upon drying behaviour [33], it is possible to establish a threshold for relative humidity as a function of the void ratio and depth in order to minimise the possibility of the creation of a tunnel excavation damage zone.

\subsection{The osmotic component}

Total suction has been selected in this study to describe the retention behaviour of shales. In order to highlight the role of osmotic suction in retention behaviour, complementary information has been

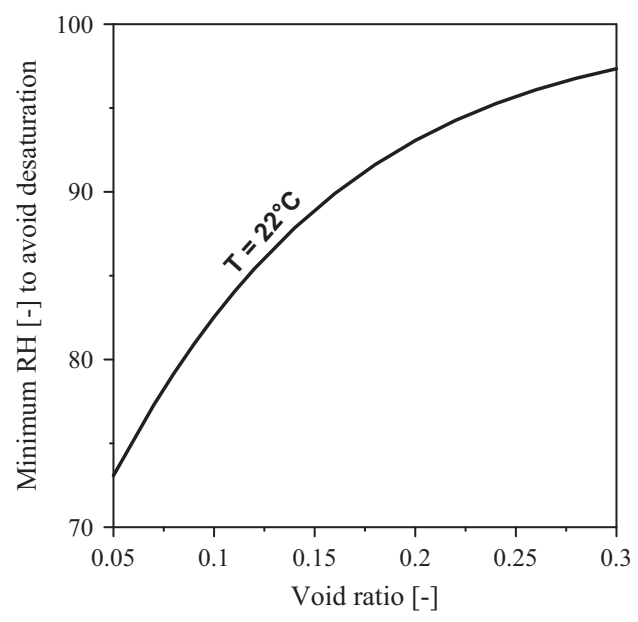

Fig. 13. Relative humidity at the air entry value.

Table 4

Results of total, matric and osmotic suction from the filter paper technique.

\begin{tabular}{lcc}
\hline & OPA-shallow & OPA-deep" $^{\prime}$ \\
\hline Shale water content & 0.068 & 0.029 \\
Total suction (MPa) & 13.3 & 76.4 \\
Matric suction (MPa) & 1.0 & 34.4 \\
Osmotic suction (MPa) & 12.3 & 42.0 \\
\hline
\end{tabular}

collected by independent measurements of the total and matric suction for two of the tested shales (OPA-shallow and OPA-deep"). The suction was measured using contact (matric suction) and noncontact (total suction) filter paper. Ad-hoc calibration curves were determined on initially oven-dried Schleicher and Schuell no. 589 filter paper. The initial oven-dried condition ensured that there was an adequate transfer of water from the specimen to the paper during the measurement. The calibration curves were obtained by applying matric suction by means of the axis translation technique and total suction by the vapour equilibrium technique to the filter paper. An equalisation time of two weeks was selected for both the calibration and the measurements. The obtained calibration curves are:

$s(\mathrm{MPa})=15.972 w_{f p}^{-3.002}$

$\psi(\mathrm{MPa})=59.076 w_{f p}^{-2.865}$

where $w_{f p}$ is the water content measured on the filter paper.

The measured total and matric suctions and computed osmotic suctions are reported in Table 4. The retention curves in terms of matric suction for the two considered shales were obtained from the MIP results (Fig. 5) using the following expression, which relates the pressure of the mercury intrusion $p$ and the matric suction for the same pore diameter:

$s=-\frac{\sigma_{w} \cos \theta_{w}}{\sigma_{H g} \cos \theta_{n w}} p=0.196 p$

where $\sigma_{w}$ and $\sigma_{H g}$ are the water and mercury surface tension values, $\theta_{w}$ is the contact angle of the air-water interface $\left(0^{\circ}\right)$, and $\theta_{n w}$ is the non-wetting contact angle between the mercury and the soil grain (taken as equal to $140^{\circ}$ ). The obtained results are depicted in Fig. 14 along with the results of the osmotic suction determination. It can be seen that the osmotic suction component explains the distance between the two curves well. This type of analysis can serve as a link between the common practice in petroleum engineering of obtaining information on the capillary 
a

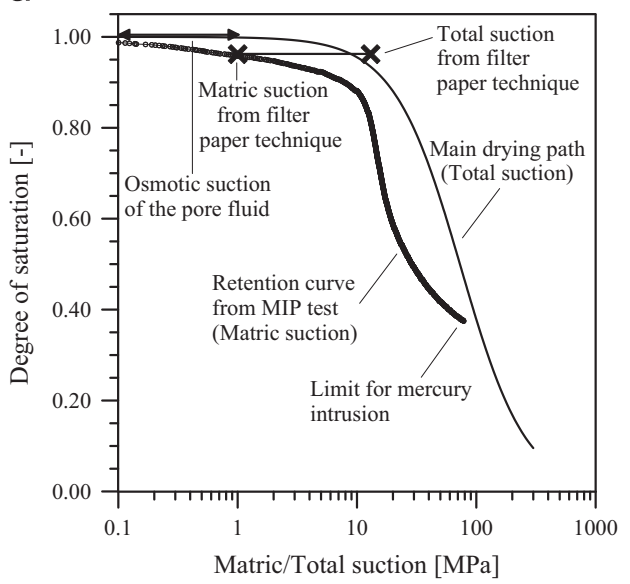

b

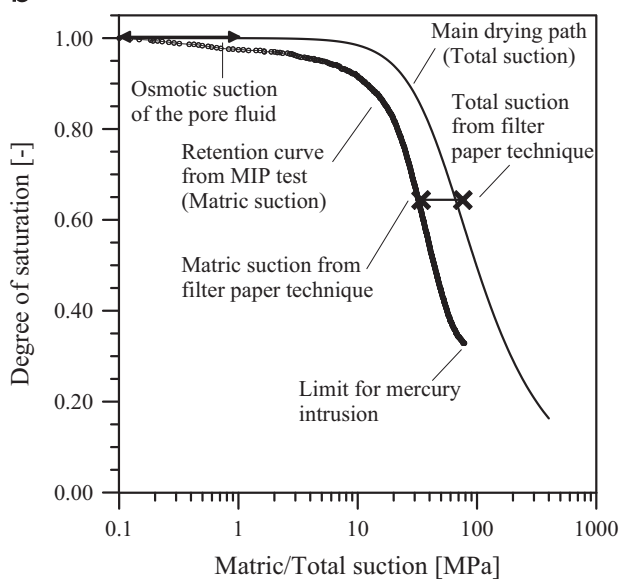

Fig. 14. Comparison of the retention curves in terms of matric and total suction and assessment of the role of the osmotic suction for Opalinus Clay at different depths (a) $\sim 300 \mathrm{~m}$, (b) $\sim 800 \mathrm{~m}$.

pressure of shales from the MIP results [21] and the proposed methodology, which uses the total suction component.

\section{Summary and conclusions}

In spite of the relevance of shale to emerging energy-related geomechanical applications for which variations in the degree of saturation are expected, the characterisation of shale retention properties has received limited attention. This paper presents the results of an experimental analysis that was designed and carried out in order to gain insight on shale retention behaviour. Testing materials with very low porosity and pore size constituted a great challenge in this investigation. We designed an advanced testing methodology that involves direct control of the shale water content and the subsequent measurement of the total suction and void ratio.

The proposed technique has been shown to be capable of capturing the important features of retention behaviour, such as the hysteresis domain and the existence of scanning paths when the shale is initially rewetted during its after-extraction state. The assessment of the volume change due to suction variation has allowed to express the retention behaviour in terms of degree of saturation, to capture the air entry value along the main drying paths, and to highlight the significant changes in porosity undergone by the shales along wetting and drying hydraulic paths.
Results from samples of different shale types, such as Opalinus Clay and Brown Dogger, have been presented. Testing different shale types allowed for the possibility to capture the important features of their retention behaviour such as the dependency of the air entry value on the void ratio. The obtained results from the tested shale samples are believed to be of great importance, considering that these materials are host rock candidates for the deep geological repository of highlevel nuclear waste. Thus, retention capacity will be a fundamental component of the ventilation (drying) and resaturation (wetting) phase of the repository.

\section{Acknowledgement}

The support of the Swiss National Cooperative for the Disposal of Radioactive Waste (NAGRA) for this research is acknowledged. The authors would like to acknowledge Patrick Dubey, Donatella Manca and Paul Witteveen, for their help with the experimental work.

\section{References}

[1] Tarantino A. Basic concepts in the mechanics and hydraulics of unsaturated geomaterials. In: Laloui L, editor. Mechanics of Unsaturated Geomaterials. New York: Wiley; 2010. p. 3-28.

[2] Romero E, Vaunat J. Retentions curves of deformable clays. In: Tarantino A Mancuso C, editors. Experimental evidence and theoretical approaches in unsaturated soils. Rotterdam: Balkema; 2000. p. 91-106.

[3] Airò Farulla C, Battiato A, Ferrari A. The void ratio dependency of the retention behaviour for a compacted clay. In: Proceedings of the 5th International Conference on Unsaturated Soils, UNSAT'10, Spain: Barcelona; 2010, p. 417-422.

[4] Vanapalli SK, Fredlund DG, Pufahl DE. The influence of soil structure and stress history on the soil-water characteristics of a compacted till. Géotechnique 1999;49(2):143-59.

[5] Romero E, Della Vecchia G, Jommi C. An insight into the water retention properties of compacted clayey soils. Géotechnique 2011;61(4):313-28.

[6] Wheeler SJ, Sharma RS, Buisson MSR. Coupling of hydraulic hysteresis and stress-strain behaviour in unsaturated soils. Géotechnique 2003;53(1):41-54.

[7] Nuth M, Laloui L. Advances in modelling hysteretic water retention curve in deformable soils. Comput Geotech 2008;35(6):835-44.

[8] Salager S, Nuth M, Ferrari A, Laloui L. Investigation into water retention behaviour of deformable soils. Can Geotech J 2013;50(2):200-8.

[9] Valès F, Nguyen Minh D, Gharbi H, Rejeb A. Experimental study of the influence of the degree of saturation on physical and mechanical properties in Tournemire shale (France). Appl Clay Sci 2004;26:197-207.

[10] Ramos da Silva M, Schroeder C, Verbrugge JC. Unsaturated rock mechanics applied to a low-porosity shale. Eng Geol 2008;97:42-52.

[11] Romero E, Gens A, Lloret A. Water permeability, water retention and microstructure of unsaturated compacted Boom clay. Eng Geol 1999;54(1-2):117-27.

[12] Laloui L, Salager S, Rizzi M. Retention behaviour of natural clayey materials at different temperatures. Acta Geotech 2013;8(5):537-46.

[13] Lima A, Romero E, Piña Y, Gens A, Li X. Water retention properties of two deep belgian clay formations. Unsaturated Soils: Res Appl 2012:179-84.

[14] Pham QT, Vales F, Malinsky L, Nguyen Minh D, Gharbi H. Effects of desaturationresaturation on mudstone. Phys Chem Earth 2007;32(8-14):646-55.

[15] Wan M, Delage P, Minh Tang A, Talandier J. Water retention properties of the Callovo-Oxfordian claystone. Int J Rock Mech Min Sci 2013;64:96-104.

[16] Schmitt L, Forsans T, Santarelli FJ. Shale testing and capillary phenomena. Int J Rock Mech Min Sci 1994;31(5):411-27.

[17] Muñoz JJ. Thermo-hydro-mechanical analysis of soft rock, application to a large scale heating test and large scale ventilation test. ( $\mathrm{PhD}$ thesis). Barcelona: Universitat Politècnica de Catalunya; 2006.

[18] Zhang CL, Rothfuchs T, Su K, Hoteit N. Experimental study of the thermohydro-mechanical behaviour of indurated clays. Phys Chem Earth 2007;32: 957-65.

[19] Villar MV, Romero FJ. Oplainus Clay 2 - phase flow parameters. FORGE Report D5 1437 p.; 2012.

[20] Romero E, Senger R, Marschall P. Air injection laboratory experiments on opalinus clay. Experimental techniques, results and analyses. 3rd EAGE Shale Workshop, Barcelona; January 23-25, 2012.

[21] Josh M, Esteban L, Delle Piane C, Sarout J, Dewhurst DN, Clennell MB. Laboratory characterisation of shale properties. J Petrol Sci Eng 2012;88:107-24.

[22] Murray EJ, Sivakumar V. Unsaturated Soils: a fundamental interpretation of soil behaviour. New York: Wiley; 2010.

[23] Leong EC, Tripathy S, Rahardjo H. Total suction measurement of unsaturated soils with a device using the chilled-mirror dew point technique. Géotechnique 2003;53(2):173-82.

[24] Cardoso R, Romero E, Lima A, Ferrari A. A comparative study of soil suction measurement using two different high-range psychrometers. In: Schanz T, 
editor. Proceedings of the 2nd International Conference on Mechanics of Unsaturated Soils, Weimar, Germany. Berlin: Springer-Verlag; 2007. p. 79-93.

[25] Fredlund DG, Rahardjo H. Soil Mechanics for Unsaturated Soils. New York: Wiley; 1993; 517.

[26] Decagon. WP4C Dewpoint Potentiameter - Operator's Manual - Decagon Devices; 2010.

[27] Péron H, Hueckel T, Laloui L. An improved volume measurement for determining soil water retention curves. Geotech Test J 2007;30(1):1-8.

[28] Ferrari A, Laloui L. Advances in the testing of the hydro-mechanical behaviour of shales. In: Laloui L, Ferrari A, editors. Multiphysical Testing of Soils and Shales. Berlin: Springer; 2012. p. 57-68.

[29] Keller LM, Schuetz P, Rossell MD, Lucas F, Gasser P, Holzer L. Characterisation of multi-scale microstructural features in Opalinus Clay. Microporous Mesoporous Maters 2013;170:83-94.
[30] Pearson FJ. Opalinus Clay experimental water: A1 Type, Version 980318. PS Internal report TM-44-98-07, Paul Scherrer Institut, Villigen PSI, Switzerland, 1998.

[31] Mäder U. Recipe and preparation of a simplified artificial pore water for Opalinus Clay and Brown Dogger. NAGRA AN 1998:11-159.

[32] Van Genuchten MT. A closed-form equation for predicting the hydraulic conductivity of unsaturated soils. Soil Sci Soc Am J 1998;44:892-8.

[33] Péron H, Hueckel T, Laloui L, Hu L. Fundamentals of desiccation cracking of fine-grained soils: experimental characterisation and mechanisms identification. Can Geotech J 1998;46(10):1177-201. 